\title{
How selecting best upfront therapy for metastatic disease? -Focus on ROS1-rearranged disease
}

\author{
Lorenza Landi^, Federico Cappuzzo^ \\ Istituto Nazionale Tumori "Regina Elena”, Roma, Italy \\ Contributions: (I) Conception and design: All authors; (II) Administrative support: L Landi; (III) Provision of study materials or patients: L Landi; \\ (IV) Collection and assembly of data: All authors; (V) Data analysis and interpretation: All authors; (VI) Manuscript writing: All authors; (VII) Final \\ approval of manuscript: All authors. \\ Correspondence to: Federico Cappuzzo, MD. UOC Oncologia Medica 2, Istituto Nazionale Tumori "Regina Elena”, Via Elio Chianesi 53, 00144 \\ Roma, Italy. Email: federico.cappuzzo@ifo.gov.it.
}

\begin{abstract}
ROS proto-oncogene 1 (ROS1) rearrangements defines a distinct group of non-small cell lung cancer (NSCLC), mainly represented by younger subjects, never smokers and with adenocarcinoma histology. Fusions involving ROS1 gene are present in 1-2\% of lung adenocarcinomas and other solid tumors. Identification of patients harboring ROS1 rearrangements is a critical issue and current guidelines recommend screening of all advanced non-squamous NSCLC and certain squamous lung cancer patients. A number of trials have supported crizotinib as the best option for NSCLC patients with ROS1 translocations, irrespective of line of therapy. Unfortunately, the majority of patients become insensitive to crizotinib, due to the occurrence of secondary ROS1 mutations or failure within the central nervous system (CNS). Several highly potent and CNS penetrant ROS1 inhibitors have been developed and recent data highlight their potential role in the front-line treatment of this disease. Among them entrectinib, also known as RXDX-101, is a potent second-generation, multitarget oral inhibitor against the neurotrophin receptors TRKA, TRKB, TRKC ALK, and ROS1 with the ability to cross the blood-brain barrier. In the next few years, results of ongoing trials with novel ROS1 inhibitors and dedicated translational research studies might help to define the optimal sequence of treatment for ROS1-positive NSCLC patients.
\end{abstract}

Keywords: ROS proto-oncogene 1 (ROS1), crizotinib, entrectinib, lorlatinib, NSCLC

Submitted Oct 10, 2020. Accepted for publication Dec 22, 2020.

doi: $10.21037 /$ tlcr-20-1109

View this article at: http://dx.doi.org/10.21037/tlcr-20-1109

\section{Introduction}

In the last decade several molecular events, including gene mutations, gene copy-number alterations, and gene rearrangements have been discovered in small fractions of lung adenocarcinomas, dramatically improving patient treatment and long-term outcomes (1). In EGFR- or $A L K$-addicted NSCLC targeted therapies are extending survival with medians ranging between $3-5$ years (2-4). Identification of ROS1 gene rearrangements further reinforced the role of targeted therapies in lung cancer $(5,6)$. The ROS1 fusion gene is detected in approximately $2 \%$ of patients with NSCLC and is associated with specific clinical and pathological features, including young age, absent or minimal smoking history, predisposition to thromboembolic events, and adenocarcinoma histology (5-8). However, such clinical features do not properly select patients for ROS1 inhibitors (ROS1-Is) and, consequently, molecular testing is mandatory (9-12). Despite current guidelines recommend to test ROS1 rearrangements at diagnosis of advanced

^ ORCID: Lorenza Landi, 0000-0003-2604-6595; Federico Cappuzzo, 0000-0002-6295-6767. 
Table 1 Summary of trials with crizotinib in advanced ROS1 rearranged NSCLC

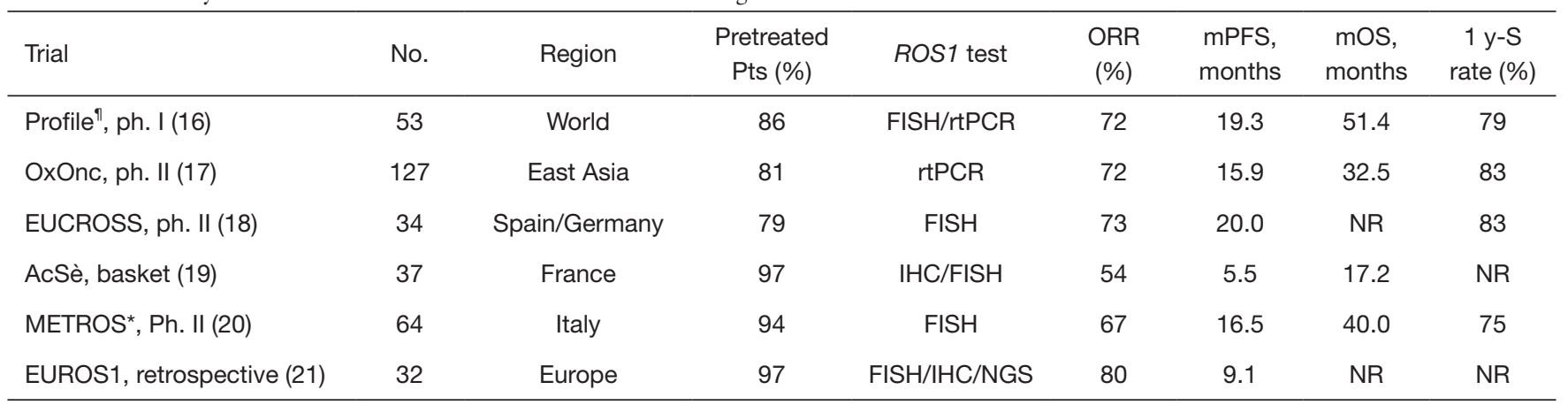

", updated results (29); *, expansion cohort (30). FISH, fluorescent in situ hybridization; rtPCR, real-time polymerase chain reaction; IHC, objective response rate; mPFS, median progression-free survival; 1 y-PFS rate, progression free survival overall survival; 1 y-S rate; survival rate at 1 year. NR, not reached.

disease, access to molecular testing and consequently to ROS1-Is remains suboptimal, as recently reported in a large patient-designed study (13). From a molecular point of view, ROS1 and ALK share a high degree of homology in their tyrosine kinase (TK) domains, thus suggesting that some ALK TK inhibitors (TKIs), such as crizotinib, may also inhibit ROS1 and preclinical models and clinical data confirmed this hypothesis $(14,15)$. In 2014, Shaw et al. published results of PROFILE 1001, in which crizotinib was offered to chemopretreated ROS1 positive NSCLC (16). Two-third of subjects obtained a reduction in their tumors and disease progression occurred in median after more than 19 months (16). Since then, a number of retrospective and prospective trials (17-21) of crizotinib have been conducted, thus providing additional data on its efficacy against such targeted population. At present crizotinib has a wellestablished role in the treatment of ROS1-positive NSCLC and is available worldwide. Unfortunately, no patient obtained a definitive cure and the majority of patients become refractory to crizotinib due to the emergence of acquired resistance, mainly sustained by the occurrence of acquired mutations or intracranial progression, highlighting once again the inadequate CNS drug penetration $(6,22,23)$. In order to overcome these limitations, novel and more potent ROS1 inhibitors have been designed and recent available data are showing encouraging results in crizotinib pretreated as well as in naïve patients (24-28).

Aim of this review is to review current and future options for front line treatment of ROS1 positive NSCLC. We present the following article in accordance with the Narrative Review reporting checklist (available at http:// dx.doi.org/10.21037/tlcr-20-1109).

\section{Crizotinib}

Table 1 summarize results of different trials of crizotinib in ROS1 rearranged advanced NSCLC. Notably, all these studies were conducted in patients pretreated with chemotherapy but naïve for ROS1 or ALK TKIs.

The first evidence of crizotinib efficacy in ROS1 addicted NSCLC derived from an expansion cohort of the PROFILE 1001, a multi-cohort, phase I study, originally designed to test the activity and safety of crizotinib in $A L K$ rearranged NSCLC (31). Further, the trial was amended to include an expansion cohort of ROS1 positive NSCLC (16), based on in vitro results showing a marked inhibitory activity of the drug against this target $(15,32)$. ROS1 cohort included 53 patients previously exposed to a median of two lines of therapy. After an additional follow-up of 3 years, update results reported a response rate (RR) of $72 \%$, with a median duration of response (DoR) of 24.7 months, and median progression-free survival (mPFS) of 19.3 months. Treatment with crizotinib also associated with a median overall survival (mOS) of 51.4 months, with more than $50 \%$ of patients alive at 48 months (30). The safety profile did not differ to that seen in the ALK-positive patients. Most common grade 1 and 2 treatment related adverse events (TRAEs) including nausea, vomiting, edema, diarrhea, and visual disorders, occurring in up to $85 \%$ of patients. Grade 3 AEs were hypophosphatemia, neutropenia and transaminases elevation, each occurring in less than $15 \%$ of cases, whereas grade 4 AEs were not reported. Notably, responses were reported irrespective of previous lines of therapy, percentage of ROS1-rearranged cells or fusion partners $(16,30)$. The favorable impact of crizotinib in the 
course of the disease coupled with a favorable safety profile, led to its worldwide approval in such population.

Beyond PROFILE 1001, a number of phase II and retrospective studies were conducted in similar populations, thus reinforcing the role of crizotinib in the treatment of ROS1 positive NSCLC (17-21). The East Asian OxOnc was the first and largest phase II trial of crizotinib in ROS1 positive NSCLC patients, detected by real-time polymerase-chain reaction (17). Among 127 patients, 23 had brain metastases (BMs) at baseline. Responses, observed in $72 \%$ of subjects, occurred rapidly (median time to objective response 1.9 months) and were durable (median DoR was 19.7 months). Neither presence of BMs nor number of prior chemotherapy lines or clinical characteristics (age, sex, smoking status or performance status) impacted on the clinical benefit. Median PFS was 15.9 months and 86\% of patients were alive at 1 year. Importantly, treatment with crizotinib improved most of lung cancer-related symptoms and quality of life. Based on these findings, crizotinib gained approval for the treatment of ROS1positive NSCLC in Japan, Taiwan, Korea, and China in 2017. The EUCROSS, a study done by the Lung Cancer Group and the Spanish Lung Cancer Group, enrolled 34 patients (18). Results were comparable with those reported in the PROFILE 1001 and in the OxOnc trials, with RR of $70 \%$ and median PFS was 20.0 months. Interestingly, this study included a translational part in which a complete molecular profile of tumor samples collected at baseline was performed. Co-occurrence of additional genetic aberrations was found in $61 \%$ of patients, with TP 53 mutations being the most frequent event (25\%). TP53-mutant/ROS1 coaltered patients progressed earlier when compared to TP 33 wild-type/ROS1 individuals ( 7.0 months versus 24.1 months, $\mathrm{P}=0.022)$. However, due to the small sample size, this finding must be interpreted with caution and do not allow to exclude any patients from treatment. The French AcSé phase II study, was intended to guarantee controlled access to crizotinib to patients potentially benefiting from the drug, such as ALK, ROS1, or MET deregulated NSCLC (19). The ROS 1 cohort included 37 patients, of which one resulted not evaluable for response. Even if RR was in line with other studies (69\%), median PFS was only 5.5 months and median OS was 17.2 months. However, differences in patient selection might account for different outcome. Indeed, in the AcSé, a quarter of patients had impaired clinical condition (ECOG PS2). The Italian METROS study aimed at investigating the activity of crizotinib in patients harboring MET deregulations or ROS 1 rearrangements (20). In the ROS1 cohort, including 26 patients, RR was $65 \%$, with an overall disease control rate (DCR) of $85 \%$. With a median follow-up of 21 months, median PFS was 22.8 months, whereas median OS was not reached. In addition, approximately $80 \%$ of subjects had the chance to be alive at 1 year. Six patients had BMs at study entry, and two received prior brain radiotherapy. Responses were observed in two cases, whereas the others obtained stabilization of their intracranial lesions. Based on these evidences the study was further emended to include additional patients and updated results confirmed the meaningful clinical benefit of treatment (30). Finally, a retrospective study conducted in several European countries evaluated the outcome of ROS1 positive NSCLC who received off-label crizotinib. Among 32 patients, RR and DCR were $80 \%$ and $86 \%$, respectively, whereas mPFS ranged 9 months, thus confirming the benefit of crizotinib even in real life population (21).

\section{Basics of acquired resistance to crizotinib}

Conventionally, mechanisms underlying acquired resistance to a target agent belong to two main categories. The first group, also known as target dependent or on-target mechanisms, involves point mutations in the kinase domain of the receptor. It was in 2013 that Awad et al. firstly reported a case of a patient with CD74-ROS1 rearranged NSCLC who failed crizotinib due to the occurrence of a secondary mutation leading to a substitution at codon 2032 in the ROS1 kinase domain (G2032R) (33). Similar to the G1202R ALK, this mutation is located in the solvent front of the kinase domain, thus causing a steric interference within the binding site (34). Interestingly, the same mutation was detected in all disease sites, supporting the hypothesis of an early clonal event. Subsequent studies demonstrated that acquired mutations are responsible for more than $50 \%$ of crizotinib failure, with the $G 2032 R$ being the most frequent $(6,22,25,26)$. Another mutation, analogous to the $A L K D 1203 N$, located in the solvent front is the D2033N which affects the ATP-binding pocket (35). Additional mutations reported in clinical samples are the S1986Y/F, the gatekeeper L2026M, the L1951R, with other recently described $(25,26)$.

The second category, also named as non-targetdependent or off-target, involves activation of other pathways. However, in crizotinib resistant ROS1 NSCLC this group seems less represented than in other oncogene addicted populations $(6,22,23)$. Finally, half of patients 
Table 2 Activity of other ROS1 inhibitors in TKIs naïve ROS1 positive NSCLC

\begin{tabular}{|c|c|c|c|c|c|c|c|c|}
\hline Drug & $\mathrm{Ph}$. & No. & $\begin{array}{l}\text { Presence of BMs } \\
\text { at baseline (No.) }\end{array}$ & $\begin{array}{l}\text { ORR } \\
(\%)\end{array}$ & $\begin{array}{l}\text { mDoR, } \\
\text { months }\end{array}$ & iRR (\%) & $\begin{array}{l}\text { mPFS, } \\
\text { months }\end{array}$ & $\begin{array}{l}\text { mOS, } \\
\text { months }\end{array}$ \\
\hline Ceritinib (24) & ॥ & $28^{\pi}$ & 8 & 62 & 21.0 & 25 & 19.3 & 24 \\
\hline Entrectinib (27) & Integrated analysis ${ }^{\S}$ & 53 & 20 & 77 & 24.6 & 55 & 19.0 & NE \\
\hline
\end{tabular}

", excluding 2 crizotinib-pretreated patients; ${ }^{\S}$, pooled analysis of ph. I and II ALKA-372-001, STARTRK-1 and STARTRK-2; *, updated results (36); BMs, brain metastases; ORR, objective response rate; mDoR, median duration of response; iRR, intracranial response rate; mPFS, median progression-free survival; mOS, median overall survival; NR, not reached; nr, not reported; NE, not estimable.

progresses by developing intracranial disease (23). This phenomenon is related to the limited blood-brain barrier penetration of crizotinib and represents a pharmacokinetic failure rather than a molecular resistance, as indicated by the absence of resistance mutations in brain tissue specimens $(6,23)$.

These considerations pointed out the need of more potent and brain penetrant agents.

\section{Other ROS1 inhibitors}

Beyond crizotinib, other ROS1 inhibitors have been evaluated or are under investigations for the treatment of ROS1 addicted disease, in both ROS1 TKIs untreated or pretreated settings. Table 2 summarizes the results of these agents in ROS1 TKIs naïve patients.

\section{Ceritinib}

Ceritinib is an oral, highly potent, and selective second generation ALK- and ROS1-inhibitor with a greater preclinical antitumor potency than crizotinib (37). In addition, the drug demonstrated in vitro inhibitory activity against the gatekeeper ROS1 L2026M mutation (38). The potential role of ceritinib against ROS1 rearranged NSCLC has been evaluated in a phase II trial conducted in 32 chemotherapy-pretreated Korean patients (24). Briefly, patients had a median age of approximately 60 years and most were female, never smokers and pretreated with three or more lines of chemotherapy. Asymptomatic or controlled $\mathrm{BMs}$ at baseline were detected in 8 patients. Interestingly, the original design of the trial allowed the enrollment of both crizotinib-pretreated and naïve individuals. However, given the lack of activity of ceritinib in the two crizotinib-refractory cases, the protocol was further restricted to crizotinib naïve only patients. Excluding the two aforementioned patients, RR and DCR were $67 \%$ and $87 \%$ respectively. Median PFS was 19.3 months, with a median DoR of 21 months, in line with results produced by crizotinib in the ROS1 cohort of PROFILE 001 trial (16). Among patients with BMs, two had measurable- and 6 had non-measurable disease; intracranial RR was $25 \%$. As already reported for ALK positive patients enrolled in the ASCEND programs, the drug safety profile emerged as a major limitation (39). Approximately a quarter of patients experienced a serious $\mathrm{AE}$, with grade 3-4 AEs occurring in $37 \%$ of cases. In addition, the majority of patients had grade $1-2$ events, including diarrhea (78\%), nausea (59\%), anorexia (56\%) and increased levels of creatinine and aminotransferases (30-40\%).

\section{Lorlatinib}

Lorlatinib is a selective, orally-administered, third generation TKI directed against ALK and ROS1 rearranged proteins and specifically designed to cross the blood-brain barrier (40). In preclinical models, lorlatinib potently inhibits ROS1 and retains activity against different ROS1 resistance mutations (41-43). So far, two prospective studies have evaluated the drug in patients with ROS1positive NSCLC $(25,26)$. In the global phase I/II, daily lorlatinib $100 \mathrm{mg}$ was given to ROS1 positive patients who were ROS1-TKIs naïve or who failed one or more ROS1 targeted agents. Primary endpoints were systemic and intracranial RR as centrally reviewed. Overall, 69 subjects were included. Of them, 21 were TKI-naïve and 48 were pretreated, with crizotinib being the most frequent ROS1 TKI previously taken. In TKI-naïve group, systemic and intracranial RR were similar (62\% and 64\%), extracranial DoR exceeded 25 months, while in the brain 
was not reached and mPSF was 21.0 months. In crizotinib pretreated group, systemic response was $35 \%$, median DoR approximately 14 months and median PFS 8.5 months. Intracranial RR was $50 \%$, with a median DoR not yet reached. For all patients, molecular profile was assessed in tissue or plasma specimens collected at baseline and during treatment. No mutations were found in cell-free DNA (cfDNA) or tissue samples from TKI naïve patients. Conversely, in pretreated patients, ROS1 mutations were detected in $15 \%$ of cfDNA samples, including $G 2032 R$ (4 cases), L2026M (1 case) and L2026M plus I2025I ( 1 case), and in $24 \%$ of tissues, including G2032R (2 cases), L2026M (1 case), S1986P (1 case) and L1991G (1 case). No responses were observed in patients harboring the G2032R. Safety profile of the drug was consistent with the one reported in ALK positive NSCLC patients (44), with hypertriglyceridaemia and hypercholesterolaemia as the most common grade 3-4 TRAES. Main grade 1-2 TRAEs (occurring in at least $10 \%$ of cases) consisted in hypertriglyceridaemia, hypercholesterolaemia, peripheral edema, neuropathy, cognitive effects, weight increase, mood effects and fatigue.

The second trial, the Italian PFROST, aimed to investigate the activity of lorlatinib in the crizotinibrefractory setting only (26). Twenty-two patients received lorlatinib $100 \mathrm{mg}$ daily until progression. Most patients were female (63\%), never smokers (59\%), with BMs (68\%) and received lorlatinib as third line therapy (72\%). Efficacy results mirrored those reported in the Phase I/II done by Shaw et al. (25), in terms of RR, intracranial RR and mPFS (40.9\%, $57 \%$ and 8.9 months, respectively). In order to define potential mechanisms responsible for lorlatinib sensitivity, pre-lorlatinib tumor tissues or plasma samples were prospectively collected. Secondary ROS1 mutations were identified in five specimens collected at baseline, including 3 G2032R and 2 novel mutations, S1861I and $V 2054 A$, each occurring in 1 case. Of note, no patient with the $G 2032 R$ mutation responded.

Taking into account, these data support the use of lorlatinib as next-line targeted agent in patients who failed crizotinib, particularly in the absence of acquired G2032R mutation. Although Food and Drug Administration (FDA) did not approve lorlatinib for ROS1+ NSCLC patients, the 2019 National Comprehensive Cancer Network (NCCN) guidelines recommend its use in patients who progressed after crizotinib or ceritinib (45). In addition, lorlatinib showed promising activity even in TKI-naïve advanced ROS1-positive NSCLC.

\section{Entrectinib}

Entrectinib is a multikinase inhibitor of the tropomyosin receptor tyrosine kinases TRKA, TRKB, and TRKC (encoded by NTRK1, NTRK2, and NTRK3 genes), ROS1 and ALK (46-48). In ROS1 driven models, entrectinib results 40 times more potent than crizotinib and it has high brain penetrance, resulting in a marked activity in orthotopic CNS xenografts that harbor the typical fusion targets of the drug (48). For such reasons, entrectinib could be particularly effective in ROS1 rearranged NSCLC. Efficacy data on entrectinib in such population come from an integrated analysis of patients enrolled in three single-arm trials, ALKA-372-001, STARTRK-1, and STARTRK-2 (27). Overall, 53 patients pretreated with prior platinum-based chemotherapy or progressed in less than 6 months after adjuvant or neoadjuvant therapy, received entrectinib at the dose of at least $600 \mathrm{mg}$ once daily. Baseline patient characteristics were typical for a ROS1 addicted population, as the majority of them were female, never smokers, with a median age of 53 years. Moreover, BMs were reported in $43 \%$ of patients and were mainly untreated (no prior radiotherapy, $65 \%$ ). ORR by blinded independent central review was $77 \%$, including a $6 \%$ of complete response. Responses were durable, with DoR of more than 24 months and mPFS reached 21 months. Among patients without BMs, systemic RR was $80 \%$ and DoR and mPFS were 24.6 and 24.3 months respectively. Among patients with CNS metastases, systemic RR was $74 \%$, iRR $55 \%$ and $\mathrm{mPFS}$ was 13.6 months. At data cut off, median survival was not estimable, with $82 \%$ of individuals alive at 18 months. One-hundred and thirty-four patients who received at least one dose of entrectinib accounted for the safety-evaluable population. Fifty-nine and $34 \%$ of patients experienced a grade $1 / 2$ or grade $3 / 4$ TRAEs, these latter including weight gain $(8 \%)$ and neutropenia (4\%). Serious TRAEs occurred in $11 \%$ of cases and were mainly nervous system $(3 \%)$ and cardiac disorders (2\%).

Based on these results, entrectinib granted both FDA [2019] and European Medicine Agency (EMA, 2020) approval as monotherapy for the treatment of adult patients with advanced ROS1 fusion-positive NSCLC not previously treated with ROS1 inhibitors.

\section{Repotrectinib}

Repotrectinib is a small, macrocyclic tyrosine kinase inhibitor of ROS1, TRK and ALK. Due to its rigid three- 
dimensional structure, it precisely binds the ATP binding pocket of the kinase and avoids steric interference from a variety of clinically resistant mutations, especially the solvent-front ROS1 G2032R (49,50). Its activity against ROS1- and NTRK-positive was initially tested in the Phase I part of the TRIDENT-1 trial, where TKI untreated $(\mathrm{N}=11)$ or pretreated $(\mathrm{N}=29)$ ROS1 positive NSCLC received repotrectinib at 9 dose levels (40 $\mathrm{mg}$ QD to 160 BID). Overall the drug was well tolerated. Most common (occurring in $>20 \%$ of patients) AEs were of grade 1 or 2 and included: dizziness, dyspnea, dysgeusia, paresthesia, fatigue, constipation, anemia, nausea and cough. Doselimiting toxicities included grade $2-3$ dizziness in 3 cases and grade 3 dyspnea and hypoxia in 1 case. The recommended phase 2 dose was established at $160 \mathrm{mg}$ BID $(28,36)$. In untreated patients, RR was $91 \%$, with $65 \%$ maintaining response at $\geq 18$ months. An encouraging intracranial activity was reported, with all the three patients with BMs at baseline obtaining response. Pretreated cohort included patients pretreated with up to 3 TKIs. In the small group of crizotinib refractory individuals $(\mathrm{N}=11)$, responses exceeded $50 \%$. Interestingly, among the 7 patients harboring the G2032R, 3 responded (36). According to these findings, FDA granted two Fast-Track designation for ROS1-positive advanced NSCLC patients, first for patients with one prior line of platinum-based chemotherapy and one prior ROS1 TKI [2019], and second for patients without prior ROS1 TKI treatment [2020]. Currently, the global phase II portion of TRIDENT-1 is ongoing and advanced ROS1 NSCLC are enrolled in four different expansion cohorts depending on the status of previous treatment with TKIs (Exp 1: ROS1 TKI-naïve, N=55; Exp 2: 1 prior ROS1 TKI and 1 platinum-based chemotherapy, $\mathrm{N}=100$; Exp 3: 2 prior ROS1 TKIs and 1 platinum-based chemotherapy, $\mathrm{N}=40$; Exp 4: 1 prior ROS1 TKI and no 1 platinum-based chemotherapy or immunotherapy) (36).

\section{Discussion}

Treatment of ROS1 rearranged NSCLC is rapidly changing, with effective drugs already available or ready to enter into clinical practice. In the last few years we have learned that (I) ROS1 positive lung cancer patients are limited in number, but their therapeutic journey could be extremely long (II) even if rare in frequency, there is no valid reason to preclude ROS1 testing to any of our patients (III) ROS1 inhibitors demonstrated efficacy irrespective of fusion partner and line of treatment and (IV) the relatively rarity of the event limits the possibility to conduct large randomized head-to-head comparative trials. With this in mind and considering only data produced in clinical trials and not regulatory indications, how to select which drug use first and which in the next line remains a major challenge in thoracic oncology.

At present, four drugs have been tested in front-line treatment: crizotinib, ceritinib, lorlatinib, entrectinib and repotrectinib (16,24-28). Even if a comparable activity to crizotinib in TKIs naïve patients has been observed, the role of ceritinib in the treatment of ROS1 rearranged NSCLC is limited and mainly affected by the unfavorable safety profile, at least when used at the daily dose of $750 \mathrm{mg}$. Moreover, no data supporting its use even at the time of crizotinib failure (24).

Crizotinib still remains a good front line option and robust data from several trials including more than threehundreds patients confirmed the substantial clinical benefit produced by this agent (16-21). Most importantly, mature data of the PROFILE 1001 showed for the first time that crizotinib prolonged survival of ROS1 patients, with median OS exceeding 4 years (29). However, even if none of the available studies specifically addressed the effective impact of crizotinib against BMs, there is a general consensus in considering brain failure as the Achilles heel of the drug $(6,23)$. Despite this, recent evidences support the efficacy of new generation and brain penetrant ROS1 TKIs in the crizotinib refractory setting or in other words support a sequential strategy $(25,26,28)$. From a practical point of view, evidence of acquired ROS1 mutations at crizotinib failure underline the retained ROS1 dependency of the disease, offering the potential to switch to another ROS1 TKIs. Indeed, lorlatinib and repotrectinib seemed to have the potential of controlling systemic and CNS lesions at the time of crizotinib failure (RR 35-57\%, intracranial RR $53-75 \%)(25,26,28)$. Furthermore, preliminary results of TRIDENT-1 suggested that repotrectinib could be effective in presence of the $G 2032 R$ mutation $(28,50)$, but confirmatory data are needed.

From another perspective, the availability of more potent ROS1 inhibitors, such as entrectinib, lorlatinib or repotrectinib, raises the question whether their use in frontline setting could produce a more durable benefit, thus delaying resistance and preventing metastatic spread within the brain. Assuming as main limitations differences in study design, sample size and maturity of data, all the three competitors, produced similar outcomes in TKI naïve populations in terms of systemic and intracranial 
response with encouraging $\mathrm{PFS}$ and manageable safety profile $(25-28,36)$.

Based on combined results of three separate trials, entrectinib recently gained approval by FDA and EMA for front line treatment of ROS1 advanced NSCLC and is replacing crizotinib in our daily practice. This agent produced durable benefit and appeared particularly effective in controlling BMs. Overall survival data are not yet mature, thus precluding to define the impact of entrectinib in long term survival. In addition, one of the future critical issue will concern the management of entrectinib-resistant cases. In the aforementioned trials, post-progression biopsies were not mandatory, consequently the molecular picture of acquired resistance to entrectinib is not defined. As mutations within the ROS1 kinase domain are the main mechanisms of resistance, reported in up to $50 \%$ of crizotinib-resistant samples $(6,22)$, it is reasonable to expect similar findings in entrectinib-resistant clones. On this base, we could consider another new generation TKIs such as lorlatinib or repotrectinib, even at the time of entrectinib failure. However, lessons learned from EGFR mutant NSCLC indicate that, when we use a more potent inhibitor in front line, by-pass signals can occur as dominant mechanisms of resistance. Indeed, a consistent fraction of osimertinib resistant patients display MET amplification, thus limiting the possibility of EGFR TKIs sequencing (51). Recently, Ku et al. attempted to identify the molecular basis of acquired resistance to entrectinib in ROS1-rearranged HCC78 cells (52). Interestingly, at NGS analysis no secondary ROS1 mutations were detected, whereas KRAS G12C and amplification of KRAS and FGF3 genes emerged as potential mechanisms of resistance. This data suggests a different binding characteristic between crizotinib and entrectinib and consequently, a different pattern of resistance. Molecular profiling done on repeated biopsy in patients who progressed on entrectinib will be crucial to define acquired resistance mechanisms and design the optimal sequential strategy. Beyond entrectinib the other NTRK/ROS1/ALK inhibitor, repotrectinib is emerging as an effective front-line option and final results of the ongoing phase II part of the TRIDENT-1 will define its place in therapy $(28,36)$.

In conclusion, patients with ROS1 rearrangement have now a long-term survival chance highlighting the relevance for ROS1 testing. In oncogene driven context, we are used to consider the most effective drug first. Crizotinib and entrectinib are two excellent front-line options and additional data are needed to establish the superiority of a drug over the other. In addition, other agents are showing promising activity in the same setting. Unfortunately, acquired resistance inevitably occurs and second-line space need to be filled before suturing the one in the previous line. We hope that in the next years, a growing amount of clinical and translation data will help us to define the optimal management of ROS1 addicted NSCLC.

\section{Acknowledgments}

Funding: This work has been partially supported by Fondazione Ricerca Traslazionale (FoRT).

\section{Footnote}

Provenance and Peer Review: This article was commissioned by the Guest Editors (Silvia Novello, Francesco Passiglia) for the series "Looking for Chimeras in NSCLC: Widen Therapeutic Options Targeting Oncogenic Fusions" published in Translational Lung Cancer Research. The article has undergone external peer review.

Reporting Checklist: The authors have completed the Narrative Review reporting checklist. Available at http:// dx.doi.org/10.21037/tlcr-20-1109

Conflicts of Interest: Both authors have completed the ICMJE uniform disclosure form (available at http:// dx.doi.org/10.21037/tlcr-20-1109). The series "Looking for Chimeras in NSCLC: Widen Therapeutic Options Targeting Oncogenic Fusions" was commissioned by the editorial office without any funding or sponsorship. FC serves as an unpaid editorial board member of Translational Lung Cancer Research from Feb 2016 to Jul 2021. LL reports personal fees from Pfizer, personal fees from AZ, personal fees from Roche, personal fees from Takeda, personal fees from BMS, personal fees from Abbott, personal fees from msd, personal fees from Bayer, from null, during the conduct of the study. FC reports personal fees from Pfizer, personal fees from $A Z$, personal fees from Roche, personal fees from Takeda, personal fees from BMS, personal fees from Eli-Lilly, personal fees from msd, personal fees from Bayer, personal fees from Boehringer Ingelheim, during the conduct of the study. The authors have no other conflicts of interest to declare.

Ethical Statement: The authors are accountable for all aspects of the work in ensuring that questions related 
to the accuracy or integrity of any part of the work are appropriately investigated and resolved.

Open Access Statement: This is an Open Access article distributed in accordance with the Creative Commons Attribution-NonCommercial-NoDerivs 4.0 International License (CC BY-NC-ND 4.0), which permits the noncommercial replication and distribution of the article with the strict proviso that no changes or edits are made and the original work is properly cited (including links to both the formal publication through the relevant DOI and the license). See: https://creativecommons.org/licenses/by-nc-nd/4.0/.

\section{References}

1. Ferrara R, Mezquita L, Besse B. Progress in the management of advanced thoracic malignancies in 2017. J Thorac Oncol 2018;13:301-22.

2. Ramalingam SS, Vansteenkiste J, Planchard D, et al. Overall Survival with Osimertinib in Untreated, EGFR-Mutated Advanced NSCLC. N Engl J Med 2020;382:41-50.

3. Solomon BJ, Kim DW, Wu YL, et al. Final overall survival analysis from a study comparing first-line crizotinib with chemotherapy: results from PROFILE 1014. J Clin Oncol 2018;36:2251-8.

4. Mok T, Camidge DR, Gadgeel SM, et al. Updated overall survival and final progression-free survival data for patients with treatment-naive advanced ALK-positive non-small-cell lung cancer in the ALEX study. Ann Oncol 2020;31:1056-64.

5. Bergethon K, Shaw AT, Ou SHI, et al. ROS1 rearrangements define a unique molecular class of lung cancers. J Clin Oncol 2012;30:863-70.

6. Gainor JF, Tseng D, Yoda S, et al. Patterns of metastatic spread and mechanisms of resistance to crizotinib in ROS1-positive non-small-cell lung cancer. JCO Precis Oncol 2017;2017:PO.17.00063.

7. Ng TL, Smith DE, Mushtaq R, et al. ROS1 Gene Rearrangements Are Associated With an Elevated Risk of Peridiagnosis Thromboembolic Events. J Thorac Oncol 2019;14:596-605.

8. Chiari R, Ricciuti B, Landi L, et al. ROS1-rearranged Non-small-cell Lung Cancer is Associated With a High Rate of Venous Thromboembolism: Analysis From a Phase II, Prospective, Multicenter, Two-arms Trial (METROS). Clin Lung Cancer 2020;21:15-20.

9. Lindeman NI, Cagle PT, Aisner DL, et al. Updated molecular testing guideline for the selection of lung cancer patients for treatment with targeted tyrosine kinase inhibitors: guideline from the College of American Pathologists, the International Association for the Study of Lung Cancer, and the Association for Molecular Pathology. J Thorac Oncol 2018;13:323-58.

10. Kalemkerian GP, Narula N, Kennedy EB, et al. Molecular testing guideline for the selection of patients with lung cancer for treatment with targeted tyrosine kinase inhibitors: American Society of Clinical Oncology endorsement of the College of American Pathologists/ International Association for the Study of Lung Cancer/ Association for Molecular Pathology clinical practice guideline update. J Clin Oncol 2018;36:911-9.

11. Ettinger DS, Aisner DL, Wood DE, et al. NCCN guidelines insights: non-small cell lung cancer, Version 5.2018. J Natl Compr Canc Netw 2018;16:807-21.

12. Planchard D, Popat S, Kerr K, et al. Metastatic non-small cell lung cancer: ESMO Clinical Practice Guidelines for diagnosis, treatment and follow-up. Ann Oncol 2018;29:iv192-iv237.

13. Parikh DA, Walia G, Freeman-Daily J, et al. Characteristics of Patients With ROS1+ Cancers: Results From the First Patient-Designed, Global, PanCancer ROS1 Data Repository. JCO Oncol Pract 2020;16:e183-e189.

14. Gainor JF, Shaw AT. Novel targets in non-small cell lung cancer: ROS1 and RET fusions. Oncologist 2013;18:865-75.

15. Huber KV, Salah E, Radic B, et al. Stereospecific targeting of MTH1 by (S)-crizotinib as an anticancer strategy. Nature 2014;508:222-7.

16. Shaw AT, Ou SHI, Bang YJ, Camidge DR, et al. Crizotinib in ROS1-rearranged non-small-cell lung cancer. N Engl J Med 2014;371:1963-71.

17. Wu YL, Yang JCH, Kim DW, et al. Phase II study of crizotinib in east asian patients with ROS1-positive advanced non-small-cell lung cancer. J Clin Oncol 2018;36:1405-11.

18. Michels S, Massutí B, Schildhaus HU, et al. Safety and Efficacy of Crizotinib in Patients With Advanced or Metastatic ROS1-Rearranged Lung Cancer (EUCROSS): A European Phase II Clinical Trial. J Thorac Oncol 2019;14:1266-76.

19. Moro-Sibilot D, Cozic N, Pérol M, et al. Crizotinib in c-MET- or ROS1-positive NSCLC: results of the AcSé phase II trial. Ann Oncol 2019;30:1985-91.

20. Landi L, Chiari R, Tiseo M, et al. Crizotinib in MET- 
Deregulated or ROS1-Rearranged Pretreated NonSmall Cell Lung Cancer (METROS): A Phase II, Prospective, Multicenter, Two-Arms Trial. Clin Cancer Res 2019;25:7312-9.

21. Mazières J, Zalcman G, Crinò L, et al. Crizotinib therapy for advanced lung adenocarcinoma and a ROS1 rearrangement: results from the EUROS1 cohort. J Clin Oncol 2015;33:992-9.

22. Lin JJ, Shaw AT. Recent Advances in Targeting ROS1 in Lung Cancer. J Thorac Oncol 2017;12:1611-25.

23. Patil T, Smith DE, Bunn PA, et al. The Incidence of Brain Metastases in Stage IV ROS1-Rearranged NonSmall Cell Lung Cancer and Rate of Central Nervous System Progression on Crizotinib. J Thorac Oncol 2018;13:1717-26.

24. Lim SM, Kim HR, Lee JS, et al. Open-Label, Multicenter, Phase II Study of Ceritinib in Patients With Non-SmallCell Lung Cancer Harboring ROS1 Rearrangement. J Clin Oncol 2017;35:2613-8.

25. Shaw AT, Solomon BJ, Chiari R, et al. Lorlatinib in advanced ROS1-positive non-small-cell lung cancer: a multicentre, open-label, single-arm, phase 1-2 trial. Lancet Oncol 2019;20:1691-701.

26. Landi L, Tiseo M, Heukamp LC, et al. Secondary ROS1 mutations and lorlatinib sensitivity in crizotinib-refractory ROS1 positive NSCLC: results of the prospective PFROST trial. Ann Oncol 2019;30:v602-v660.

27. Drilon A, Siena S, Dziadziuszko R, et al. Entrectinib in ROS1 fusion-positive non-small-cell lung cancer: integrated analysis of three phase 1-2 trials. Lancet Oncol 2020;21:261-70.

28. Drilon A, Cho BC, Kim D, et al. Safety and preliminary clinical activity of repotrectinib in patients with advanced ROS1/TRK fusion-positive solid tumors (TRIDENT-1 study). Ann Oncol 2019;30:v159-v193.

29. Shaw AT, Riely GJ, Bang YJ, et al. Crizotinib in ROS1rearranged advanced non-small-cell lung cancer (NSCLC): updated results, including overall survival, from PROFILE 1001. Ann Oncol 2019;30:1121-26.

30. Chiari R, Landi L, Tiseo M, et al. Crizotinib In ROS1 rearranged NSCLC: Final Results of The Metros Trial. Tumori J 2019;105:86-87.

31. Kwak EL, Bang YJ, Camidge DR, et al. Anaplastic lymphoma kinase inhibition in non-small-cell lung cancer. N Engl J Med 2010;363:1693-703.

32. Yasuda H, de Figueiredo-Pontes LL, Kobayashi S, et al. Preclinical rationale for use of the clinically available multitargeted tyrosine kinase inhibitor crizotinib in ROS1- translocated lung cancer. J Thorac Oncol 2012;7:1086-90.

33. Awad MM, Katayama R, McTigue M, et al. Acquired resistance to crizotinib from a mutation in CD74-ROS1. N Engl J Med 2013;368:2395-401.

34. Katayama R, Shaw AT, Khan TM, et al. Mechanisms of acquired crizotinib resistance in ALK-rearranged lung cancers. Sci Transl Med 2012;4:120ra17.

35. Drilon A, Somwar R, Wagner JP, et al. A Novel Crizotinib-Resistant Solvent-Front Mutation Responsive to Cabozantinib Therapy in a Patient with ROS1-Rearranged Lung Cancer. Clin Cancer Res 2016;22:2351-8.

36. Doebele RC, Lin JJ, Nagasaka M, et al. TRIDENT-1: A global, multicenter, open-label Phase II study investigating the activity of repotrectinib in advanced solid tumors harboring ROS1 or NTRK1-3 rearrangements. J Clin Oncol 2020;38:abstr TPS9637.

37. Marsilje TH, Pei W, Chen B, et al. Synthesis, structureactivity relationships, and in vivo efficacy of the novel potent and selective anaplastic lymphoma kinase (ALK) inhibitor 5-chloro-N2-(2-isopropoxy-5-methyl-4(piperidin-4-yl)phenyl)-N4-(2-(isopropylsulfonyl)phenyl) pyrimidine-2,4-diamine (LDK378) currently in phase 1 and phase 2 clinical trials. J Med Chem 2013;56:5675-90.

38. Dziadziuszko R, Le AT, Wrona A, et al. An activating KIT mutation induces crizotinib resistance in ROS1-positive lung cancer. J Thorac Oncol 2016;11:1273-81.

39. Hou H, Sun D, Liu K, et al. The safety and serious adverse events of approved ALK inhibitors in malignancies: a meta-analysis Cancer Manag Res 2019;11:4109-18.

40. Johnson TW, Richardson PF, Bailey S, et al. Discovery of (10R)-7-amino-12-fluoro-2,10,16-trimethyl-15-oxo10,15,16,17-tetrahydro-2H-8,4-(metheno)pyrazolo[4,3-h] [2,5,11]-benzoxadiazacyclotetradecine-3-carbonitrile (PF-06463922) a macrocyclic inhibitor of anaplastic lymphoma kinase (ALK) and c-ros oncogene 1 (ROS1) with preclinical brain exposure and broad-spectrum potency against ALK-resistant mutations. J Med Chem 2014;57:4720-44.

41. Gainor JF, Dardaei L, Yoda S, et al. Molecular mechanisms of resistance to first- and second-generation ALK inhibitors in ALK-rearranged lung cancer. Cancer Discov 2016;6:1118-33.

42. Zou HY, Li Q, Engstrom LD, et al. PF-06463922 is a potent and selective next-generation ROS1/ALK inhibitor capable of blocking crizotinib-resistant ROS1 mutations. Proc Natl Acad Sci USA 2015;112:3493-8.

43. Facchinetti F, Loriot Y, Kuo MS, et al. Crizotinib-resistant 
ROS1 mutations reveal a predictive kinase inhibitor sensitivity model for ROS1- and ALK-rearranged lung cancers. Clin Cancer Res 2016;22:5983-91.

44. Solomon BJ, Besse B, Bauer TM, et al. Lorlatinib in patients with ALK-positive non-small-cell lung cancer: results from a global phase 2 study. Lancet Oncol 2018;19:1654-67.

45. Available online: https://www.nccn.org/professionals/ physician_gls/pdf/nscl.pdf

46. Drilon A, Siena S, Ou SI, et al. Safety and antitumor activity of the multitargeted pan-TRK, ROS1, and ALK inhibitor entrectinib: combined results from two phase I trials (ALKA-372-001 and STARTRK-1). Cancer Discov 2017;7:400-9.

47. Rolfo C, Ruiz R, Giovannetti E, et al. Entrectinib: a potent new TRK, ROS1, and ALK inhibitor. Expert Opin Investig Drugs 2015;24:1493-500.

48. Ardini E, Menichincheri M, Banfi P, et al. Entrectinib,

Cite this article as: Landi L, Cappuzzo F. How selecting best upfront therapy for metastatic disease?-Focus on ROS1rearranged disease. Transl Lung Cancer Res 2020;9(6):26862695. doi: 10.21037/tlcr-20-1109 a pan-TRK, ROS1, and ALK inhibitor with activity in multiple molecularly defined cancer indications. Mol Cancer Ther 2016;15:628-39.

49. Drilon A, Ou SHI, Cho BC, et al. Repotrectinib (TPX0005) Is a Next-Generation ROS1/TRK/ALK Inhibitor That Potently Inhibits ROS1/TRK/ALK Solvent-Front Mutations. Cancer Discov 2018;8:1227-36.

50. Yun MR, Kim DH, Kim SY, et al. Repotrectinib Exhibits Potent Antitumor Activity in Treatment-Naïve and Solvent-Front-Mutant ROS1-Rearranged Non-Small Cell Lung Cancer. Clin Cancer Res 2020;26;3287-95.

51. Ramalingam S, Cheng Y, Zhou C, et al. Mechanisms of acquired resistance to first-line osimertinib: Preliminary data from the phase III FLAURA study. Ann Oncol 2018;29:viii740.

52. $\mathrm{Ku} \mathrm{BM}$, Bae YH, Lee KY, et al. Entrectinib resistance mechanisms in ROS1-rearranged non-small cell lung cancer. Investigational New Drugs 2020;38:360-8. 